\title{
(IN)JUSTICE AND MORALITY. A COMMENTARY ON CHRISTOPH HORN'S PAPER
}

\author{
(IN)JUSTIÇA E MORALIDADE. UM COMENTÁRIO SOBRE O ARTIGO \\ DE CHRISTOPH HORN
}

ALESSANDRO PINZANI ${ }^{1}$

(UFSC/Brazil)

\begin{abstract}
The paper is a commentary on Christoph Horn's paper The Concept of Justice. It criticizes Horn's claim that justice is overrated in contemporary philosophical debate by discussing Horn's arguments. In doing so, it questions (1) the idea that we can easily distinguish between morally central and peripheral questions, as Horn claims; it points out (2) that this distinction is based on the values held by those who are drawing it; and finally (3) it stresses the centrality of the feeling of outrage provoked by the action whose acceptability is being challenged. Finally, it claims that morality arises from the experience of injustice and, therefore, that questions of justice are not only morally central; they are, rather, essential to morality.
\end{abstract}

Key-words: Justice. Morality. Injustice.

Christoph Horn's article is extremely dense and thoroughly thought provoking. It contains many remarks I agree with almost entirely, such as the distinction among the different kinds of justice. However, in the present text I shall focus on the points that I consider more controversial. In other words, I shall present here a subjective choice of topics among the many touched upon by Horn.

The main criticism advanced by Horn is that justice is overrated in contemporary philosophical debate. One could of course reply that this depends on how you define it. It is therefore not by chance that Horn dedicates the first part of his paper to the definition of justice - more precisely to the discussion of the definitions used by authors such as Mill and Rawls in different contexts. An important distinction, which Horn insists upon, is the one between personal and institutional justice, but it would be wrong to identify the first one with the field of morality and the second one with that of politics. Furthermore, it is possible to 
identify at least ten classes of possible objects of justice and eight different meanings of justice, as Horn points out. But from the point of view of a semantic definition of justice, it is particularly relevant to distinguish between the absolute and the relational, or interpersonal, concepts of justice. The first can be reduced to the Ciceronian and Ulpianian formula suum cuique tribuere: justice has to do with the fact that people get what they deserve or what is due to them. The second concept implies the existence of interpersonal comparisons: does person A get the same as B or more than B? And was this equality or difference justified? I shall come back to this distinction.

As I have said, Horn's main criticism has to do with the relevance of justice in contemporary philosophical debate. He tries to justify this appraisal by criticizing the idea that justice lies at the core of morality. He distinguishes between morally central and morally peripheral questions of justice. It is not completely clear to me how Horn make this distinction. In the example of people standing in a line within a bakery, Muhammad is not served because of his race, while Sandra is not served because the seller gives preference to a friend. In the first case, we have a case of racial discrimination which represents a form of belittlement of the person and of misrecognition. In the second case, however, we are faced with a situation that may be unfair, but it is a much less severe case of partiality, namely that of privileging friendship over correctness. But what makes the two cases normatively different? The object of (in)justice (race on one side versus my right as next in the line on the other)? The attitude of the seller (racist in one case, partial to friends in the other)? The grade of indignation provoked by this attitude (high in one case, low in the other)? Let us start with this last aspect. Whose indignation is relevant here? It could be that Muhammad is so used to being racially discriminated against that he does not even react with indignation, but with sadness or even with shame, if he has interiorized the racial prejudice. Conversely, Sandra might feel so outraged by the unfair preference given to the seller's friend that she falls into a fit of rage that many people would judge as completely disproportionate. So, should we consider only the reaction of an impartial observer Tom? What if Tom is a committed racist but puts impartiality and fairness over every other value? He would feel more outraged by the injustice experienced by Sandra than by the one experienced by Muhammad. In other words, in a racist context, not serving someone because of his or her race could be an acceptable attitude or represent just a morally peripheral matter. And in a society in which impartiality and fairness are the top values, undue preference accorded to a friend could represent a capital violation of the moral code. Of course, this is not tantamount to negating the existence of morally central and peripheral questions. What I would like to do is rather: (1) to question the 
idea that we can easily distinguish between them; (2) to point out that this distinction is based on the values held by those who are drawing it; and finally (3) to stress the centrality of the feeling of outrage provoked by the action whose acceptability is being challenged. I shall now go on to investigate these three points more deeply.

I shall discuss point (1) and point (2) together. Let us introduce another comparison which should make Horn's position clearer: we cannot put on the same level the kinds of social injustice suffered by the global poor or by the weakest members of society, on the one hand, and the suffering experienced by the supporters of a football team, wronged by an unjust decision by the referee (picking up on an example mentioned by Horn). Yet, there might be some particularly fanatical supporters who elevate the results of their team above that of everything else. We might consider this silly or even outrageous (outrage, again...), but we need to justify this. Why it is morally unacceptable that a football fan considers it more important that justice be done to his team than to the global poor? Our judgment of his behavior relies evidently on a hierarchy of moral values that we consider objectively valid: it is not just our subjective preference for the poor against his subjective preference for his team. We think that certain issues have objectively a greater moral relevance than others and we think this because we have (or we think that we have) good reasons for it. We can offer arguments to support the claim that the suffering of the poor is morally more relevant than the suffering of football fans, and the main argument has to do with the object of the injustice suffered by both groups: while the poor are threatened in their very physical survival, the fans experience frustration over the score of a football game. Horn does agree with this and lists a number of goods, which he calls morally central, among which he mentions: survival, physical health, bodily integrity, social and political autonomy, etc. Goods such as spare time interests, travel habits, musical or artistic taste etc., on the contrary, do not lie at the center of our moral concerns and can be deemed as peripheral. Once again, I agree with him, but I ask myself, and him as well, how we come to this list of central goods? Through empirical studies, as some anthropologists suggest? Do we rely on the idea of a human nature common to every person? Or do we try to define the material conditions that everyone needs to satisfy in order to be a moral agent or, more basically, to be a person, to survive and to act more or less autonomously? Or do we appeal to some moral intuition?

All these four possible strategies seem to me to share a premise. They all start from the presupposition that it is possible to identify some common core from which morality can be built or can arise (depending on your belief in moral constructivism, realism, naturalism, etc.). 
And I believe that Horn does share this premise. So, let us examine it. This will lead us to discuss the third point mentioned above, that one that relates to our feeling of outrage when faced with injustice.

Let me first outline my argument. Independently of how you define morality (as a system of principles and norms that aims at regulating human behavior; as the philosophical debate on these principles and norms; as an anthropological phenomenon that is apparently present in every human culture and whose roots might lie in our brain, i.e. in our neurological structure, as claimed by many authors nowadays) you must refer to some basic phenomenon that gives rise to it. I claim that this phenomenon is precisely the experience of injustice and, therefore, that questions of justice are not only morally central; they are, rather, essential to morality.

Let us start with some remarks from a quite naturalistic point of view of ethics. I shall adopt this point of view for the argument's sake, not necessarily because I share it. Many contemporary authors who study the evolutionary basis of morality have come to the conclusion that we developed our most basic and most general moral values and principles (i.e. those values and principles that are not culture specific) as a reaction to experiences of injustice, particularly of unfairness and ingratitude, which in every human culture are condemned without exception - while, in almost every culture, exceptions are made with regard to acts like killing or even incest, which might be permitted under certain circumstances and under certain conditions. I shall not discuss these scholars' explanations: some claim e.g. that unfairness and ingratitude are deleterious from an evolutionary point of view (they would either make cooperation in a group impossible, or isolate an individual in the group to the point of compromising her or his chances of survival). Rather, what I would claim is that experiences of injustice, particularly of unfairness and ingratitude, do not merely play an important role within morality; they are, in fact, at its very core.

To use another distinction drawn by Horn, morality is, in the first place, a relational kind of justice (particularly when gratitude is involved), but it can be also an absolute one. One could even go as far as to claim that even religion, or at least religious ethics, arises from the experience of what we could call, following Horn's classification, "cosmic injustice". "Why is this happening to me? What did I do to deserve it? Maybe I did something wrong, even if I did not harm anyone. Maybe I offended some invisible person or violated some ethic@ - Florianópolis v.13,n.1, p. 18 -26,Jun. 2014. 
unwritten order. There must be a reason that justifies my situation because, on the contrary, it would be utterly unfair". The idea that evils inflicted upon us for no apparent reason might be the punishment for violating some divine moral code is a good argument for not seeing those evils as unjust. But any further discussion of this idea is beyond the scope of this commentary.

Going back to Horn's example of the racist seller, we could claim that racism is despicable because it is unjust, because it treats persons differently, because it discriminates among them, even if they are equal from every morally relevant point of view (skin color does not represent such a relevant point of view). The same is true of slavery in the example of the quarrel between Achilles and Agamemnon. Slavery is unjust for the same reason that racism is: it treats differently persons who are morally equal. Once you admit this, the quarrel between the two Greek heroes becomes similar to that of robbers about their haul (see below). On the other hand, one could claim that in Homeric times slavery was considered morally legitimate and that, therefore, Achilles's complaint should be considered as justified or unjustified in this historical context, and not from the point of view according to which slavery is immoral. In any case, both from a universalistic and from a relativistic point of view, we are dealing with questions of justice and fairness.

Does this all mean that every moral question can be reduced to a matter of justice? At the risk of overstating the position, we would claim that, in a sense, it is quite correct. Almost every time we violate what we consider to be our moral duty, we are being unjust towards someone, sometimes even towards ourselves. Morally inappropriate behavior elicits a feeling of outrage among observers that can be assimilated to the 'original' feeling of injustice. When someone is killed in a robbery, we are outraged because it is an undeserved, therefore unjust, death not merely because a life was taken (this might cause sadness or despair, even when the death is morally justifiable: in the case of legitimate self-defense, for instance, or of soldiers, or of someone sacrificing oneself in order to save another person's life). But if the robber's life is seen as an act of self-defense, we do not think this is morally wrong, because we do not see this as being unjust (on the contrary, someone would see it as a form of justice). When someone steals our property, we feel outraged because the act of stealing is unfair, independently of the value of the stolen objects. Then again, if someone steals to avoid death by starvation, we tend to consider this act forgivable, because it would be disproportionate, therefore unjust, to put the right to property over the right to life. 
So, it seems that questions of justice are morally central, and, furthermore, that morally relevant questions are very often also questions of justice.

I would now like to address one last aspect of Horn's paper. While discussing different critiques of egalitarianism, Horn shares their basic claim, namely that the relational kind of justice is misleading and leads to neglect the absolute kind. He then goes on to criticize the absolute view of justice or, more properly, its centrality to morality. He once again holds that morally central questions concern certain fundamental goods, whose worth does not depend on their just or unjust distribution. I disagree. Taking from someone these goods is perceived to be morally wrong not in itself, but only when it is perceived to be unjust. Let us take again the example of killing. If a soldier kills an enemy who was pointing a weapon against him, we do not consider this to be morally wrong (at least generally). However, if a soldier kills a harmless civilian who does not pose any threat to him, we are outraged and consider this morally wrong. Why? Because this represents an unjust act (in an absolute sense). If a shop owner loses his customers to a competitor because the latter is nicer to them or is more capable of doing business, we do not consider this morally problematic. They are competing on the same level for the same customers. It is akin to two children who compete over two slices of cake, agreeing that the winner will take all. If, however, a big retail chain kills all the small enterprises of a town, we are outraged, because it would be like an adult taking away the whole cake from a group of children. What is at stake here is not the fact that someone will remain without cake, but how they are going to lose their share.

Even in the case of morally peripheral questions, justice is relevant. Both the moral outrage of the football supporters and that of the neglected customer are perfectly legitimate, since the actions of the referee and of the seller contradict their sense of justice, even if it concerns a trivial matter.

In my opinion, it is problematic to claim, on the one hand, that morally relevant questions concern fundamental goods such as survival, bodily integrity etc., while simultaneously claiming that the distribution of these goods is not central to morality. Yet, once you admit that the distribution of these goods is central to morality, then you are admitting that justice is central to morality.

Horn might reply that my use of the term "justice" incurs the same semantic confusion he criticizes in Mill and other writers. But this accusation could be turned against him, since ethic@-Florianópolis v.13,n.1,p.18-26,Jun. 2014. 
his characterization of justice seems to go against its meaning, both in natural language and in philosophical discussion, once it is disconnected from the distribution of the fundamental goods that constitute the core object of morality according to Horn's own position. If Horn wants to undertake a semantic analysis (as he claims), why does he start with conceptual distinctions and not with everyday language?

Sometimes different meanings of "just" are used in Horn's analysis. Let's take the example of Bernadette, the killing nun: Horn claims that the fact that Herbert accused her unjustly of being unjust, while she always was just in her charity work, does not justify her killing him. Of course it does not. But let us consider what the word "just" viz. "unjust" means here. In the case of Herbert's accusation, "unjust" means "false and unjustified". In his accusation, on the other hand, Herbert accused Bernadette of being "unjust" in the sense of "unfair". And Bernadette was "just" in her charity work to the extent that she was trying to realize some form of "distributive" or even "restorative" justice (depending on her belief - or not - that the poor are victims of society's unjust structure and rules, and have the right, therefore, to compensation). Horn further claims that, in killing Herbert, Bernadette is not acting unjustly, but just immorally. As a matter of fact, however, she acted unjustly, both in the sense that her act was not justified (i.e., based on objective grounds, not only on her legitimate but only subjectively felt anger against Herbert's false allegation) and in the sense that it is disproportionate (therefore against commutative justice) to kill someone for a petty misdemeanor like a false accusation of unfairness.

Horn's examples of a band of robbers or of charitable nuns are interesting also in another sense. What makes their actions morally despicable viz. admirable is precisely their being unjust viz. just. Robbers act immorally because they steal, i.e. they take away from people their property, without having a right or another good reason for doing it. But if the band in question were formed by Robin Hood and his merry fellows, stealing from the vicious and unjust Sheriff of Nottingham in order to help the poor people unjustly exploited by him, we would not condemn them morally, because they would be just practicing corrective justice. Also nuns doing charity work are practicing a form of corrective justice: they are distributing free meals among the poor, not among rich peoples - and we consider their action admirable precisely for this reason; but that gives them no right to privilege Carl the funny guy, and the poor people queuing to get their meals would have every reason to complain, even if they feel grateful to the nuns and consider their work morally admirable (once again: in the sense of distributive or restorative justice). 
By focusing on questions such as dividing the haul or giving preferential treatment to Carl, Horn switches our attention from the main question at stake: why do we condemn or admire the actions of robbers versus nuns? At the same time, by claiming that the robbers' stealing and the nuns' charity have nothing to do with either justice or injustice, he is offering an incomplete vision of morality and justice, since he should show us that those actions can be labeled as morally right or wrong independently of their just or unjust character. Yet, it seems impossible to do so without resorting implicitly to the idea of a just distribution of the fundamental goods that are central to morality. 
${ }^{1}$ Federal University of Santa Catarina (UFSC), Florianópolis, Brazil. E-mail: alepinzani@gmail.com

Recebido / Received: 29/05/2014

Aprovado / Approved: 13/06/2014

ethic@- Florianópolis v.13, n.1, p. 18 -26, Jun. 2014. 